\title{
BMJ Open Characteristics and short-term outcomes of young women with acute myocardial infarction in Malaysia: a retrospective analysis from the Malaysian National Cardiovascular Database registry
}

To cite: Venkatason $P$, Zubairi YZ, Zaharan NL, et al. Characteristics and short-term outcomes of young women with acute myocardial infarction in Malaysia: a retrospective analysis from the Malaysian National Cardiovascular Database registry. BMJ Open 2019;9:e030159. doi:10.1136/ bmjopen-2019-030159

- Prepublication history and additional material for this paper are available online. To view these files, please visit the journal online (http://dx.doi. org/10.1136/bmjopen-2019030159).

Received 01 March 2019 Revised 18 September 2019 Accepted 29 October 2019
Check for updates

(c) Author(s) (or their employer(s)) 2019. Re-use permitted under CC BY-NC. No commercial re-use. See rights and permissions. Published by BMJ.

For numbered affiliations see end of article.

Correspondence to Dr Ahmad Syadi Mahmood Zuhdi; syadizuhdi@yahoo.co.uk

\section{ABSTRACT}

Objective Young women form a minority but an important group of patients with acute myocardial infarction (MI) as it can potentially cause devastating physical and socioeconomic impact. This study was aimed to investigate the characteristics and outcomes of young women with $\mathrm{Ml}$ in Malaysia.

Design This is a retrospective analysis of women with ST-elevation MI (STEMI) and non-STEMI (NSTEMI) from 18 hospitals across Malaysia using the Malaysian National Cardiovascular Database registry-acute coronary syndrome (NCVD-ACS).

Participants Women patients diagnosed with acute Ml from year 2006 to 2013 were identified and divided into young (age $\leq 45, n=292$ ) and older women (age $>45$, $\mathrm{n}=5580$ ).

Primary outcome measure Comparison of demographics, clinical characteristics and in-hospital management was performed between young and older women. In-hospital and 30-day all-cause mortality were examined.

Results Young women (mean age $39 \pm 4.68$ ) made up $5 \%$ of women with $\mathrm{Ml}$ and were predominantly of Malay ethnicities (53.8\%). They have a higher tendency to present as STEMI compared with older women. Young women have significantly higher rates of family history of premature coronary artery disease (CAD) $(20.5 \%$ vs $7.8 \% \mathrm{p}<0.0001)$. The prevalence of risk factors, such as hypertension, diabetes and dyslipidaemia was high in both groups. The primary reperfusion strategy was thrombolysis with no significant differences observed in the choice of intervention for both groups. Other than aspirin, rates of prescriptions for evidence-based medications were similar with $>80 \%$ prescribed statins and aspirin. The all-cause mortality rates of young women were lower for both in-hospital and 30 days, especially in those with STEMI with adjusted mortality ratio to the older group, was 1:9.84.

Conclusion Young women with MI were over-represented by Malays and those with a family history of premature CAD. Preventive measures are needed to reduce cardiovascular risks in young women. Although in-hospital
Strengths and limitations of this study

- This study was performed using data on a large number of multiethnic women patients from 18 major hospitals across Malaysia.

- The clinical outcome is all-cause mortality. No description of cardiovascular-related mortality.

- There are many other non-participating hospitals of which patients were not taken into analysis.

No long-term follow-up.

management was similar, short-term mortality outcomes favoured young compared with older women.

\section{INTRODUCTION}

Acute myocardial infarction (MI) is a predominantly male disease. Women, especially those of premenopausal age are at lesser risk of MI due to the protective effect of their sex hormones. ${ }^{12}$ In the Framingham Heart Study, the incidence of an MI in women aged 35 to 44 years over a 10-year follow-up was 5.2/1000 compared with $38.2 / 1000$ in men of the same age group. ${ }^{3}$ In women, the highest incidence of MI occurred in those of 50 to 54 years old age group $(23.1 \%) .{ }^{4}$ There was also evidence of a strong inverse association between age at menopause and coronary heart disease (CHD) risk. ${ }^{5}$

Malaysia is a unique multiethnic country in South East Asia, of which the prevalence of cardiovascular risk factors is rising ${ }^{6}$ due to changes in lifestyle. CHD is currently the second cause of mortality in women in this country $(10.5 \%)^{7}$ in the year 2017 ; thus, there is a need to examine this issue in our women population for further improvement of service. In a study that examined Malaysian 
patients with the acute coronary syndrome (ACS) from the year 2006 to 2010 ( $\mathrm{n}=13591$ ), it was found that nearly a quarter (24\%) of patients were women and they had more risk factors, less likely to undergo intervention and had higher mortality compared with men. ${ }^{8}$

Although the incidence is rather low, the impact of MI on young women's childbearing years, their active lifestyle and their socioeconomic status can be devastating. An earlier study between 2006 and 2008 showed that $1.9 \%$ of Malaysian patients with ACS were young women in the reproductive age group (20 to less than 40 years old). ${ }^{9}$ Young women showed a higher postinfarction mortality in hospital and up to 1 year after discharge in comparison to men $(4.23 \%$ vs $2.21 \%, \mathrm{p}=0.005) .{ }^{10}$ There is a shortage of studies that have attempted to explore the characteristics and clinical outcomes of young women in this population compared with older women, and hence more information is required for this particular group.

This study used data from the Malaysian National Cardiovascular Database registry-acute coronary syndrome (NCVD-ACS) to examine the clinical characteristics of young women with MI and their outcomes compared with older women of over 45 years old. This registry is part of the NCVD registry whereby 18 hospitals across Malaysia recorded information on patients with cardiovascular diseases from the year 2006 till current.
This database provided valuable information on cardiovascular disease in this region of the world.

\section{METHODS}

\section{Study subjects and data collection}

The Malaysian NCVD-ACS registry is a prospective registry sponsored by the Ministry of Health, Malaysia (MoH) and cosponsored by the National Heart Association of Malaysia (NHAM). This registry included information on demographic information, cardiovascular diagnosis, comorbidities, family history, in-hospital management and on-discharge medications for adult patients in Malaysia who presented with cardiovascular disease at the participating hospitals. The details of the registry have been described in detail elsewhere. ${ }^{11}$

Anonymous patient data were obtained from this registry to identify women patients admitted with ST-elevation MI (STEMI) and non-ST elevation MI (NSTEMI) from the year of 2006 to 2013. Patients who were identified were divided into two categories: women aged 45 and below, also considered as young women similar to the definition used in the PRIMVAC Register ${ }^{12}(\mathrm{n}=292)$ and women above the age of $45(\mathrm{n}=5580)$. Those above the age of 45 will be known as older women. Sample size calculation was not included in the analysis as the frame

Table 1 Baseline characteristics, risk factors and comorbidities of young (age $\leq 45$ and older (age $>45$ ) women with acute Ml in the Malaysian NCVD-ACS registry from the year 2006 until the year 2013

\begin{tabular}{|c|c|c|c|}
\hline & $\begin{array}{l}\text { Young women }(n=292) \\
N, \% \text { or mean } \pm S D\end{array}$ & $\begin{array}{l}\text { Older women }(n=5580) \\
N, \% \text { or mean } \pm S D\end{array}$ & $P$ value \\
\hline Age* (Year) $^{*}$ & $39.0 \pm 4.68$ & $62.0 \pm 10.02$ & $<0.001$ \\
\hline \multicolumn{4}{|l|}{ Ethnicity } \\
\hline Malay & $157(53.8 \%)$ & 2626 (47.1\%) & \\
\hline Chinese & $38(13.0 \%)$ & $1312(23.5 \%)$ & $<0.001$ \\
\hline Indian & $68(23.3 \%)$ & $1347(24.1 \%)$ & \\
\hline Others & $29(9.9 \%)$ & $295(5.3 \%)$ & \\
\hline \multicolumn{4}{|l|}{ Risk factors } \\
\hline Smoker (active/ex) & $27(9.6 \%)$ & $533(10.2 \%)$ & 0.738 \\
\hline Dyslipidaemia & $84(37.8 \%)$ & $2032(46.7 \%)$ & 0.010 \\
\hline Hypertension & $143(57.7 \%)$ & $4321(82.8 \%)$ & $<0.001$ \\
\hline Diabetes mellitus & $136(55.7 \%)$ & $3261(64.2 \%)$ & 0.007 \\
\hline Family history of premature CAD & $60(20.5 \%)$ & $437(7.8 \%)$ & $<0.001$ \\
\hline \multicolumn{4}{|l|}{ Comorbidities } \\
\hline Cerebrovascular disease & $8(3.2 \%)$ & $271(5.6 \%)$ & 0.114 \\
\hline Peripheral vascular disease & $4(1.6 \%)$ & $53(1.1 \%)$ & 0.452 \\
\hline Chronic lung disease & $4(1.6 \%)$ & $157(3.2 \%)$ & 0.159 \\
\hline Congestive heart failure & $20(6.8 \%)$ & $534(9.6 \%)$ & 0.144 \\
\hline Chronic renal failure & $13(5.3 \%)$ & 633 (13.0\%) & $<0.001$ \\
\hline
\end{tabular}

All $\mathrm{p}$ values were calculated using the $\chi^{2}$ test unless stated; *t-test.

CAD, coronary artery disease. 
of the study was chosen from the objective of studying women with two categories of age. All data were extracted from the original raw data.

Variables obtained from the database for the purpose of this study were demographic variables such as age, ethnicity (Malay, Chinese, Indian and others), risk factors such as smoking status, diabetes, hypertension, dyslipidaemia and family history of premature coronary artery disease (CAD), comorbidities such as cerebrovascular disease, peripheral vascular disease, chronic lung disease, congestive heart failure and chronic renal failure, ACS diagnosis (STEMI, N-STEMI), type of Killip classes (I-IV), cardiac enzymes (peak troponin I, creatine kinase (CK), CK-MB) and left ventricular ejection fraction (LVEF). The in-hospital intervention included were thrombolysis, percutaneous coronary intervention (PCI) and coronary artery bypass grafting (CABG) surgery. Evidencebased medications were defined as classes of drugs which carried outcome benefit and recommended in clinical guidelines ${ }^{13}$ which include antiplatelets (aspirin and ADPreceptor antagonist), angiotensin-converting enzyme inhibitors (ACEIs) or angiotensin receptor blockers (ARBs), lipid-lowering medications (statins only) and beta-adrenoceptor blockers (beta-blockers).

\section{Endpoints}

The primary outcome for this study was in-hospital allcause mortality. The secondary outcome is 30-day postdischarge all-cause mortality. The mortality status of the patients (dead or alive) was cross-checked with the Malaysian Death Register for further verification.

\section{Ethics consent}

The NCVD registry study was approved by the Medical Review \& Ethics Committee (MREC), Ministry of Health $(\mathrm{MOH})$ Malaysia in 2007 (Approval Code: NMRR-07-20250). MREC waived informed consent for NCVD.

\section{Statistical analysis}

Categorical variables were described as frequency and percentages while continuous variables were expressed as mean and $\mathrm{SD}$ or median with IQR if skewed. Comparison in demographic and clinical characteristics between young women and older women were performed using the $\chi^{2}$ test, Fisher's exact test, Student's t-test or Wilcoxon rank-sum test (if skewed) as appropriate. Missing data for explanatory variables were assumed to be missing at random. Data of $110(0.02 \%)$ women were missing from the 5872 women. Since the missing value was minimal, we omitted those values from subsequent analysis.

A generalised linear model with a log link, binomial distribution and a robust variance estimator was used to estimate the risk ratios. The risk ratios represent the relative risk for mortality of young women and older women patients. Variables that were statistically significantly different (a two-sided $\mathrm{p}$ value of less than 0.05 ) between young women and older women, that were of clinical importance, and that had satisfactory outcomes in the respective subcategories were adjusted for in the model. Variables with satisfactory outcomes were considered relevant as they were frequently associated with the dependent variable.

Statistical significance was considered if the $p$ value was less than 0.05 , and the $95 \%$ CI of risk ratios excluded the

Table 2 Clinical presentations of young (age $\leq 45$ and older (age $>45$ ) women with acute MI in the Malaysian NCVD-ACS registry from the year 2006 until year 2013

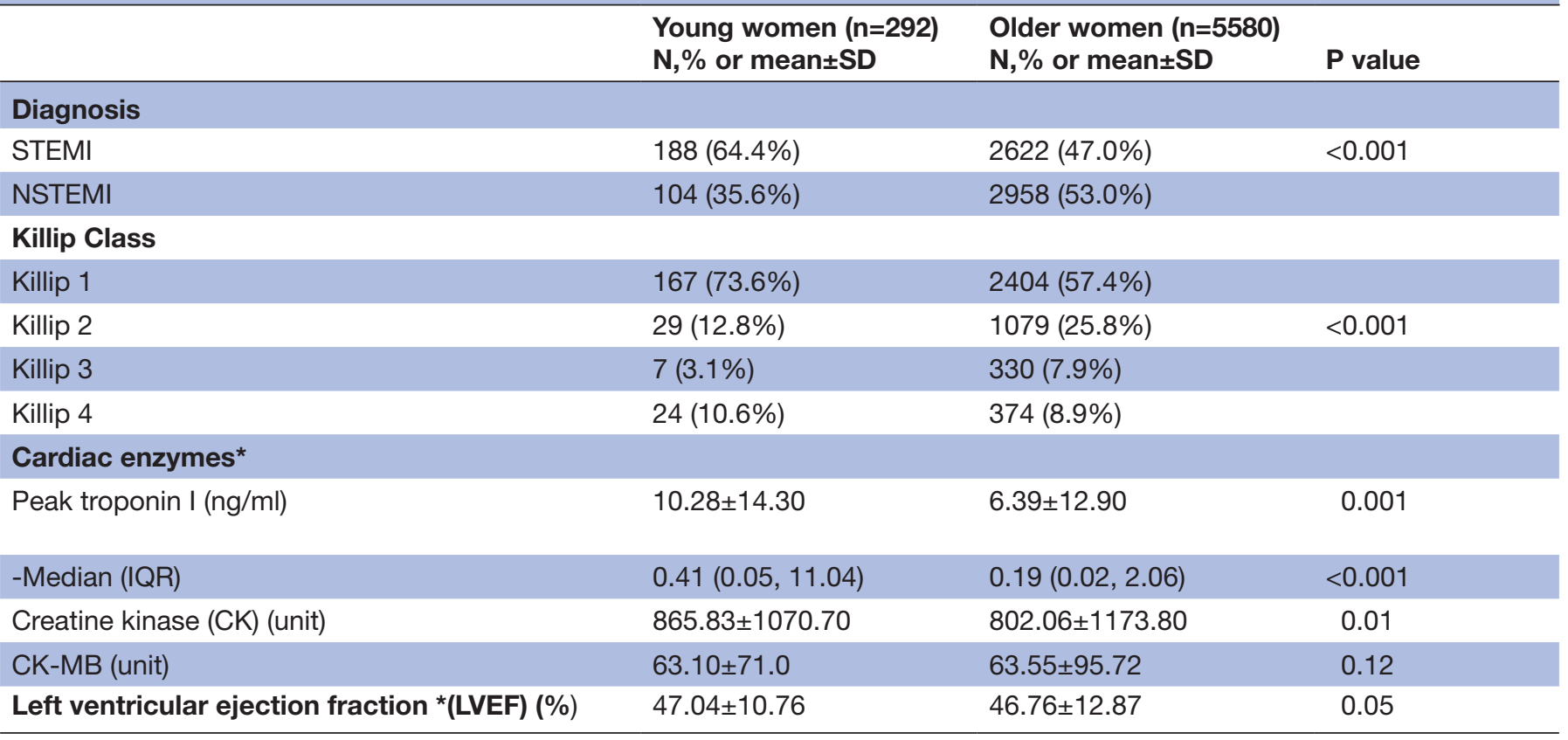

Note: All $\mathrm{p}$ values were calculated using the $\chi^{2}$ test unless stated; *t-test. 
value of 1 . All analyses were conducted using SPSS statistical software (V21, IBM SPSS Statistics, USA).

\section{Patient and public involvement}

There was no patient or public participation in the development of this study's research question and outcome. All data were obtained retrospectively from the Malaysian NCVD-ACS. Result of this study will not be disseminated to study participants.

\section{RESULTS}

Baseline characteristics and clinical presentation

Young women made up only $5 \%(n=292)$ of the total women patients who presented with ACS in the Malaysian NCVD registry $(\mathrm{n}=5872)$. Malay ethnicity group was more predominant in young women (table 1). Young women have less cardiovascular risk factors compared with older women except for a premature family history of CAD. Young women presented more with STEMI and Killip 1 class compared with older women, as shown in table 2. Although CK and troponin levels were significantly higher in young women, the LVEF was similar between the two groups.

\section{In-hospital invasive coronary revascularisation and evidence- based pharmacotherapy}

Intravenous thrombolysis was the mainstay of reperfusion therapy in both groups (table 3). No significant difference was found between young and older women in terms of intravenous thrombolysis. However, the door-to-needle time for young women was slightly longer. The rate of PCI was similar. More than $80 \%$ of women patients were prescribed aspirin and statins. Aspirin was prescribed more in young women while the rest of the medications were similarly prescribed in both groups. The length of hospital stay was significantly shorter for young women.

\section{Early clinical outcomes of in-hospital and 30-day all-cause mortality}

The in-hospital and 30-day all-cause mortality outcomes are presented in tables 4 and 5, respectively. Mortality rates between the two groups differed significantly in favour of young women. Young women had significantly lower in-hospital and 30-day all-cause mortality across all strata of ACS type. They showed a more favourable outcome compared with older women with an adjusted mortality risk ratio of 1:9.84, respectively. The gap in mortality rates of young women to the older group significantly increased at 30 days in the NSTEMI subgroup. The adjusted mortality risk for older women increased from 5.58 at in-hospital to 9.084 at 30 days.

\section{DISCUSSION}

This study describes the clinical characteristics and outcome of young women with acute MI in the Malaysian population. Young women (aged 45 years or less)

Table 3 In-hospital intervention, evidence-based pharmacotherapy and length of hospital stay comparing young (age $\leq 45$ and older (age >45) with acute MI in the Malaysian NCVD-ACS registry from the year 2006 until year 2013

\section{Young women $(\mathrm{n}=182)$ \\ Older women $(\mathbf{n}=\mathbf{2 5 4 7 )}$ \\ $\mathrm{N}, \%$ or mean \pm SD $\quad \mathrm{N}, \%$ or mean \pm SD $\quad$ P value}

\begin{tabular}{llll}
\hline Thrombolysis & & & \\
Given & $126(69.2 \%)$ & $1742(68.4 \%)$ & 0.400 \\
Not given - proceeded to PCl & $15(8.2 \%)$ & $218(8.6 \%)$ & \\
Not given - missed & $30(16.5 \%)$ & $421(16.5 \%)$ & $14(0.5 \%)$ \\
Not given - patient refusal & $3(1.6 \%)$ & $152(6.0 \%)$ & \\
Not given - contraindicated & $8(4.4 \%)$ &
\end{tabular}

Door to needle time (minutes)

$\begin{array}{llll}\text { (Median +/-IQR) } & 60 & 57 & <0.001\end{array}$

Percutaneous coronary intervention

$\begin{array}{llll}\text { STEMI } & 53(29.3 \%) & 599(24.5 \%) & 0.151 \\ \text { NSTEMI } & 17(18.1 \%) & 381(13.8 \%) & 0.244 \\ \text { CABG Surgery } & 1(0.4 \%) & 56(1.0 \%) & 0.160\end{array}$

Evidence-based pharmacotherapy

\begin{tabular}{llll} 
Aspirin & $244(92.4 \%)$ & $4187(85.7 \%)$ & 0.002 \\
ADPA & $149(72.0 \%)$ & $2671(69.4 \%)$ & 0.437 \\
\hline ACEl/ARB & $141(49.3 \%)$ & $2639(48.8 \%)$ & 0.864 \\
Beta blocker & $180(69.5 \%)$ & $3070(64.8 \%)$ & 0.120 \\
Statin & $234(89.0 \%)$ & $4120(84.9 \%)$ & 0.072 \\
Length of hospital stay (days) & $5.33 \pm 3.96$ & $6.18 \pm 8.04$ & 0.023 \\
Median +/-IQR & $4.00(3.00,5.75)$ & $4.00(3.00,6.00)$ & 0.035 \\
\hline
\end{tabular}


Table 4 Comparison of in-hospital mortality between young (age $\leq 45$ and older (age $>45$ ) Malaysian women presented as unadjusted and adjusted risk ratio (RR) with $95 \% \mathrm{Cl}$

\begin{tabular}{|c|c|c|c|c|c|c|}
\hline & $\begin{array}{l}\text { Number of } \\
\text { patients }\end{array}$ & $\begin{array}{l}\text { Deaths } \\
\text { n (\%) }\end{array}$ & $\begin{array}{l}\text { Unadjusted risk ratio } \\
(95 \% \mathrm{Cl})\end{array}$ & $P$ value & $\begin{array}{l}\text { Adjusted risk ratio* } \\
(95 \% \mathrm{Cl})\end{array}$ & $P$ value \\
\hline \multicolumn{7}{|c|}{ All patients $(n=5761)$} \\
\hline Older women & 5474 & $660(12.1 \%)$ & 6.23 (4.90 to 7.56$)$ & $<0.001$ & 6.58 (5.01 to 7.94$)$ & $<0.001$ \\
\hline \multicolumn{7}{|c|}{ STEMI $(\mathrm{n}=2748)$} \\
\hline Older women & 2563 & $411(16.0 \%)$ & 9.45 (8.21 to 10.43$)$ & 0.001 & 9.84 (8.74 to 10.92$)$ & $<0.001$ \\
\hline \multicolumn{7}{|c|}{ NSTEMI $(n=3013)$} \\
\hline Young women & 102 & $3(2.9 \%)$ & Reference & & Reference & \\
\hline Older women & 2911 & 249 (8.6\%) & 5.21 (4.56 to 6.87 ) & 0.044 & 5.58 (4.97 to 7.02$)$ & 0.023 \\
\hline
\end{tabular}

*Adjusted for are age, ethnicity, dyslipidaemia, hypertension, diabetes, family history of premature CAD, chronic renal failure, Killip class, door to needle time, aspirin, statin and $\mathrm{PCl}$.

made up only $5 \%$ of the women patients in our nationwide registry. They have a higher tendency to present as STEMI compared with older women, although they have lower rates of cardiovascular risk factor profile. Interestingly, young women have significantly higher rates of family history of premature CAD. The primary reperfusion strategy for STEMI remained pharmacological with intravenous thrombolytic agents instead of the preferred catheter-based approach. No significant differences were observed in the choice of intervention for both groups. Other than aspirin, the rates of prescriptions for evidence-based medications were similar. The in-hospital mortality and mortality at 30 days were lower for the younger patients, especially in those with STEMI.

Traditionally, the impact of CAD on women has always been underestimated as CAD is often believed to be a 'man's disease.' Changes in cultural and socioeconomic structures through recent years see young women projecting themselves as frontliners in Malaysia's workforce. Majority of Malaysian women have incomegenerating jobs and remain as central figures in their children care and upbringing. ${ }^{7}$ Thus, to suffer from a debilitating illness is equally devastating for women as it is for men. The low prevalence of young women in this study is consistent with other previous reports. ${ }^{5} 1415$ Future studies should explore how to further model this finding for the projection of future disease burden in the country.

There seemed to be a Malay ethnic predilection in young women with MI. Malaysian women in the general population comprise mainly of Malays $(54.9 \%)$ followed by Chinese $(24.1 \%)$, Indian $(7.4 \%)$ and others $(20.0 \%){ }^{7}$ There was also an over-representation of the Indian ethnicity in both young and older women. This disproportionately high number of Indian ethnics among MI cohort has also been reported previously in Singapore, a neighbouring Asian country with demography quite similar to the Malaysian population. ${ }^{16}$ Racial tendency

Table 5 Comparison of 30-day mortality between young (age $\leq 45$ and older (age $>45$ ) Malaysian women presented as unadjusted and adjusted risk ratio (RR) with $95 \% \mathrm{Cl}$

\begin{tabular}{|c|c|c|c|c|c|c|}
\hline & $\begin{array}{l}\text { Number of } \\
\text { patients }\end{array}$ & $\begin{array}{l}\text { Deaths } \\
\text { n (\%) }\end{array}$ & $\begin{array}{l}\text { Unadjusted risk ratio } \\
(95 \% \mathrm{Cl})\end{array}$ & $P$ value & $\begin{array}{l}\text { Adjusted risk ratio* } \\
(95 \% \mathrm{Cl})\end{array}$ & $P$ value \\
\hline \multicolumn{7}{|c|}{ All patients $(n=5872)$} \\
\hline Young women & 292 & $18(6.2 \%)$ & Reference & & Reference & \\
\hline Older women & 5580 & 853 (15.3) & 8.01 (7.01 to 9.56$)$ & $<0.001$ & 8.57 (7.85 to 10.12$)$ & $<0.001$ \\
\hline \multicolumn{7}{|c|}{ STEMI ( $\mathrm{n}=2810)$} \\
\hline Young women & 188 & $15(8.0 \%)$ & Reference & & Reference & \\
\hline Older women & 2622 & $490(18.7 \%)$ & 9.05 (8.09 to 11.34$)$ & $<0.001$ & 9.87 (9.01 to 12.93$)$ & $<0.001$ \\
\hline \multicolumn{7}{|c|}{ NSTEMI $(n=3062)$} \\
\hline Young women & 102 & $3(2.9 \%)$ & Reference & & Reference & \\
\hline Older women & 2958 & $363(12.3 \%)$ & 8.95 (7.41 to 9.21$)$ & 0.004 & 9.08 (7.98 to 10.82 ) & 0.002 \\
\hline
\end{tabular}

${ }^{*}$ Adjusted for are age, ethnicity, dyslipidaemia, hypertension, diabetes, family history of premature CAD, chronic renal failure, Killip Class, door to needle time, aspirin, statin and PCl. 
in young women with MI could be related to our finding of a higher rate of family history of premature CAD. Genetic backgrounds may play an essential role in MI predisposition in young women population, and thus, molecular studies should be undertaken to explore this further.

The rates of conventional risk factors in young women in our study were higher than the national prevalence of the diseases. Of those young women with MI, $58 \%$ have hypertension compared with $32 \%$ national prevalence, $55 \%$ have diabetes (12\% national prevalence) and 38\% have dyslipidemia (7\% national population) (NHMS III).${ }^{17}$ The low prevalence of smoking in our young women $(10 \%)$ is consistent with the finding among young women with acute MI in Singapore. ${ }^{18}$ This pattern is different from the Western population as cigarette smoking is reported as the predominant risk factor among young women. ${ }^{511} 19$ We do not have information in the registry on emerging non-traditional risk factors of $\mathrm{MI}$ in women such as hypertensive disorders in pregnancy, gestational diabetes, preterm delivery and depression ${ }^{20}$ and, thus, these factors were not considered in this study. However, our findings suggest that despite the possibility of other unique variables which may contribute to the incidence of acute MI in young women, traditional risk factors remain important.

The majority of acute MI patients would present to hospitals that are not equipped for acute angiography/ angioplasty and subsequently would receive thrombolysis. ${ }^{21}$ In this study, more than half of young women received thrombolysis (69.2\%) as compared with $43 \%$ of young women 50 years and below in New Jersey. ${ }^{22} \mathrm{PCI}$ and CABG were less preferred among young women in this study. As young Malaysian women had a lower mortality rate as compared with the older group, they showed better prognosis after fibrinolytic therapy. ${ }^{23}$ Evidence-based cardiovascular medicines for secondary prevention are recommended as secondary preventative cardiovascular therapy to reduce the risk of recurrent events. ${ }^{24}$ Some studies have shown that women were less likely to receive appropriate pharmacotherapy after $\mathrm{MI}^{24}$ The rate of prescribing of antiplatelet and statins in both young and older women in this population is satisfactory and adhere to international guidelines. The prescribing of ACEIs/ ARBs and beta-blockers in our women were consistent with findings from previous studies on Malaysian population with $\mathrm{MI}^{25}$ and may reflect the prescribing preference in this country.

The door to needle time for young women is longer than for older women. This finding may reflect the relative lack of clinical suspicion of acute MI in young women, and hence, the longer time is taken to achieve a diagnosis and initiate treatment. However, the mortality for both in-hospital and at 30 days was higher in older women. Thus, it seems that age itself is a significant independent predictor of mortality in women with MI. More worryingly, the short-term mortality from MI for Malaysian is higher than Western counterparts, ${ }^{26}$ and this may require measures to improve diagnosis and management strategies in this population.

This study used data from a well-maintained national cardiovascular registry and can provide information on cardiovascular disease in this region of the world. As this study used registry-based data, there are inherent limitations. There were other non-participating hospitals in the country, and thus there may be selection bias. There is a possibility of intercentre variation, which is presented in the online supplementary figure $1 \mathrm{a}, \mathrm{b}$. The study sample size is rather small, as our objective was focused on young women. MI in young women could be underestimated as young women who presented with symptoms of MI may not be investigated as such. There may be information that is not captured in the database, such as underlying diagnosis of spontaneous coronary artery dissection (SCAD) and drug use or abuse in young women that could possibly influence management and outcome. LVEF was used as estimates of patients' functional status as information on New York Heart Association classification were incomplete. The in-hospital and 30-day mortality outcomes were measures of short-term clinical outcome. Unfortunately, at the moment, data were not available for long-term outcome in this registry.

\section{CONCLUSION}

Young women are a minority group of patients with MI in our nationwide cardiovascular registry. Ethnicity and family history of premature cardiovascular disease may play a role in the predisposition of MI in these young women patients. Young women with MI do have higher rates of cardiovascular risk factors compared with the national population, and this needs to be addressed in preventative strategies. The short-term mortality outcomes favoured young compared with older women in both STEMI and NSTEMI.

Author affiliations

${ }^{1}$ Department of Medicine, University of Malaya Faculty of Medicine, Kuala Lumpur, Malaysia

${ }^{2}$ Foundation Studies in Science, Universiti Malaya, Kuala Lumpur, Wilayah Persekutuan, Malaysia

${ }^{3}$ Department of Pharmacology, University of Malaya Medical Centre, Kuala Lumpur, Wilayah Persekutuan, Malaysia

${ }^{4}$ Cardiology Unit, Department of Medicine, University of Malaya Medical Centre, Kuala Lumpur, Malaysia

Acknowledgements We would like to thank all the medical and non-medical staffs involved in the data collection and organization of NCVD-ACS Malaysia.

Contributors The original idea of the study originated from ASMZ. PV, YZZ, NAMS, and ASMZ designed the study. PV, YZZ and NLZ performed all data and statistical analysis. All authors interpreted the results. WAWA, MIAH, MFH, NAMS, NLZ and MDI wrote the initial draft of the manuscript. PV, NLZ, MIAH, MFH, YZZ, WAWA, and MDI revised the manuscript. All authors scrutinized the final manuscript.

Funding The authors have not declared a specific grant for this research from any funding agency in the public, commercial or not-for-profit sectors.

Competing interests None declared.

Patient consent for publication Not required. 
Ethics approval The NCVD registry study was approved by the Medical Review \& Ethics Committee (MREC), Ministry Of Health (MOH) Malaysia in 2007 (Approval Code: NMRR-07-20-250). MREC waived informed consent for NCVD.

Provenance and peer review Not commissioned; externally peer reviewed.

Data availability statement No data are available.

Open access This is an open access article distributed in accordance with the Creative Commons Attribution Non Commercial (CC BY-NC 4.0) license, which permits others to distribute, remix, adapt, build upon this work non-commercially, and license their derivative works on different terms, provided the original work is properly cited, appropriate credit is given, any changes made indicated, and the use is non-commercial. See: http://creativecommons.org/licenses/by-nc/4.0/.

\section{REFERENCES}

1 Mendelsohn ME, Karas $\mathrm{RH}$. The protective effects of estrogen on the cardiovascular system. N Engl J Med 1999;340:1801-11.

2 Subbiah MTR. Mechanisms of cardioprotection by estrogens. Exp Biol Med 1998;217:23-9.

3 Gordon T, Kannel WB, Hjortland MC, et al. Menopause and coronary heart disease. The Framingham study. Ann Intern Med 1978;89:157-61.

4 Roger VL, Go AS, Lloyd-Jones DM, et al. Heart disease and stroke statistics--2012 update: a report from the American Heart Association. Circulation 2012;125:e2-220.

5 Doughty M, Mehta R, Bruckman D, et al. Acute myocardial infarction in the young--the University of Michigan experience. Am Heart $J$ 2002;143:56-62.

6 Amiri M, Majid HA, Hairi F, et al. Prevalence and determinants of cardiovascular disease risk factors among the residents of urban community housing projects in Malaysia. BMC Public Health 2014;14 Suppl 3:S3.

7 DOSM. Available: https://www.dosm.gov.my [Accessed 6 Sep 2019].

8 Lu HT, Nordin R, Wan Ahmad WA, et al. Sex differences in acute coronary syndrome in a multiethnic Asian population: results of the Malaysian national cardiovascular disease database-acute coronary syndrome (NCVD-ACS) registry. Glob Heart 2014;9:381-90.

9 Idris N, Aznal SS, Chin SP, et al. Acute coronary syndrome in women of reproductive age. Int $J$ Womens Health 2011;3:375-80.

10 Egiziano G, Akhtari S, Pilote L, et al. Sex differences in young patients with acute myocardial infarction. Diabet Med 2013;30:e108-14.
11 Mähönen MS, McElduff P, Dobson AJ, et al. Current smoking and the risk of non-fatal myocardial infarction in the who MONICA project populations. Tob Control 2004;13:244-50.

12 Morillas PJ, Cabadés A, Bertomeu V, et al. [Acute myocardial infarction in patients under 45 years]. Rev Esp Cardiol 2002;55:1124-31.

13 Simon GE, Psaty BM, Hrachovec JB, et al. Principles for evidencebased drug formulary policy. J Gen Intern Med 2005;20:964-8.

14 Egred M, Viswanathan G, Davis GK. Myocardial infarction in young adults. Postgrad Med J 2005;81:741-5.

15 Zimmerman FH, Cameron A, Fisher LD, et al. Myocardial infarction in young adults: angiographic characterization, risk factors and prognosis (coronary artery surgery study registry). J Am Coll Cardiol 1995;26:654-61.

16 Mak K-H, Chia K-S, Kark JD, et al. Ethnic differences in acute myocardial infarction in Singapore. Eur Heart $J$ 2003;24:151-60.

17 Institute of Public Health,. Ministry of health Malaysia. The third National health morbidity survey (NHMS III) report. Kuala Lumpur: Institute of Public Health, 2006.

18 Xie CB, Chan MY, Teo SG, et al. Acute myocardial infarction in young Asian women: a comparative study on Chinese, Malay and Indian ethnic groups. Singapore Med J 2011;52:835-9.

19 Yandrapalli S, Nabors C, Goyal A, et al. Modifiable risk factors in young adults with first myocardial infarction. J Am Coll Cardiol 2019;73:573-84.

20 Garcia M, Mulvagh SL, Merz CNB, et al. Cardiovascular disease in women: clinical perspectives. Circ Res 2016;118:1273-93.

21 Zupan I, Noc M, Trinkaus D, et al. Double vessel extension of spontaneous left main coronary artery dissection in young women treated with thrombolytics. Cathet Cardiovasc Intervent 2001;52:226-30.

22 Garg S, Nashed AH, Roche LM. Fibrinolytic therapy in young women with acute myocardial infarction. Ann Emerg Med 1999;33:646-51.

23 Buijs JE, Uyttenboogaart M, Brouns R, et al. The effect of age and sex on clinical outcome after intravenous recombinant tissue plasminogen activator treatment in patients with acute ischemic stroke. J Stroke Cerebrovasc Dis 2016;25:312-6.

24 Smolina K, Ball L, Humphries KH, et al. Sex disparities in postacute myocardial infarction pharmacologic treatment initiation and adherence: problem for young women. Circ Cardiovasc Qual Outcomes 2015;8:586-92.

25 Venkatason P, Zaharan NL, Ismail MD, et al. Trends and variations in the prescribing of secondary preventative cardiovascular therapies for non-ST elevation myocardial infarction (NSTEMI) in Malaysia. Eur J Clin Pharmacol 2018;74:953-60.

26 Chan MY, Du X, Eccleston D, et al. Acute coronary syndrome in the Asia-Pacific region. Int J Cardiol 2016;202:861-9. 